\title{
Diverging Patterns of Satisfaction across Europe
}

\author{
Zoltán Kmetty \\ MTA-E LTE-Peripato Research Group, Budapest, Hungary \\ Sociology Department, Faculty of Social Sciences, Eötvös Loránd University, \\ Budapest, Hungary \\ zkmetty@tatk.elte.hu \\ Róbert Tardos \\ MTA-ELTE-Peripato Research Group, Budapest, Hungary
}

\begin{abstract}
Building on a decade-long comparative database of the European Social Survey the present study targets general aspects of satisfaction across larger regions of Europe with special regard to the socioeconomic changes in the recent decades. Conventionally cultivated measures like central tendency are supplemented by structural parameters of distribution based on a conceptual scheme distinguishing consensus and tightness of opinions. Dispersion-like indicators point to a stronger polarization of public mood under worse off contexts and, to a certain degree, conditions of vulnerability to economic downturn. A more rigid juncture of various mood components is also observable under less favourable circumstances. Disparities of income position in the first place, but features of cultural and ideological-political differentiation as well are intertwined with satisfaction polarization in a kind of stress syndrome exhibiting substantial divergences in both the East/West and the North/South regards.
\end{abstract}

\section{Keywords}

economic crisis - European Social Survey - satisfaction - polarization - attitude constrain

* The study joins the research program Crisis and Social Innovation by the MTA-ELTE Peripato Research Group. We are grateful for the comments and suggestions received at a session of the May 2014 Budapest RC28 Conference. 


\section{$1 \quad$ Conceptual Frames}

\subsection{Problems and Approach}

This study deals with patterns of satisfaction attitudes under various regional and temporal settings. This paper considers both the level and the dispersion of satisfaction. Although measuring levels and dispersion may both prove important in studying subjective well-being, comparative research has devoted much less attention to the latter. This paper intends to address this gap by relying on distribution-oriented structural approaches such as presented by Blau (1994), but also other streams of research targeting subjective aspects of social differentiation. While the polarization of opinions on cultural and moral issues is a primary theme (more so in the United States than in Europe), aspects of satisfaction have received less study in such a frame.

Patterns of convergence or the divergence of subjective indicators can be treated on various levels, ranging from the individual through the countrywide to larger regional contexts beyond national units. Comparative analysis may target each of these foci; the present paper will concentrate primarily on the latter. It has been well documented in the literature that, in accordance with regional differences of development, levels of satisfaction vary significantly across Europe. In the frames of a broader international survey, Deaton (2008) pointed to the clearly low levels of life satisfaction in the countries of Eastern Europe and the former Soviet Union. While between-country differences present a natural and often targeted focus, the extent to which the within-country variation follows a similar pattern has received less attention, even though this has significant implications. If it is the case that distribution patterns by countries or larger regions add to differences in the level of well-being, such a constellation might adversely affect regional disparities, and on a larger horizon social cohesion and development.

The analyses presented here are mostly of an explorative character in regard to new research targets. Based on the data from the 2002-2012 waves of the European Social Survey (three waves preceding the financial crisis in the fall of 2008 and three following) the explication of this paper will start by an overall outline of relationships between various measures of variation of satisfaction on the one hand, and indicators of level and dynamics of economic development on the other. As a next step of investigations, analyses will be shown on the linkages of satisfaction polarization and structural and cultural-ideological diversity. The characteristics of larger European regions and the changes over the past decade will be especially highlighted. 
1.2

1.2.1

\section{The Differentiation of Satisfaction Attitudes}

Following Simmel's (1955) initiatives on the emergence of differentiation, Blau (1994) formalized structural parameters of distribution patterns regarding various social positions like heterogeneity, inequality and consolidation/ intersection that expressing the correlations between positions on various dimensions. Though the original formulations concerned tangible goods (such as income, education, job status, etc.) in the first place, their application is open to diversity patterns of subjective manifestations, too.

The issue of the polarization of us public opinion served as an important impetus to conceptualizations along related lines after the 1990s. Following attempts by DiMaggio et al. (1996) to outline a more complex scheme of analysis, and seeking to operationalize attitude-constraint in a multidimensional way, Martin (2002) introduced a distinction between 'consensus' and 'tightness'. The former regards a conventional focus of research on polarization indicating the degree of agreement between members of a social entity. The latter regards a further trait, namely the degree of interrelation among various attitude facets held by distinct individuals. Although power impacts on attitude organization may entail the co-occurrence of consensus and tightness (in terms of the present subject, this means e.g. a high degree of satisfaction and a high correlation among its various components), other patterns are also conceivable. ${ }^{1}$ As this paper will detail later, Martin introduced the measure of relative entropy, a tool of measurement further elaborated by Linzer (2006) to operationalize attitude constraint. In order to grasp the related aspect of satisfaction patterns, this tool has been used in the current analysis.

\subsubsection{Opinion Polarization and Its Structural and Cultural-Ideological Embedding}

Structural theories of differentiation ascribe a central role to distribution characteristics with regard to social diversity and inequality and the linkages of various positions. The distribution of various resources (such as income or other assets) may itself have implications on the shape of the opinions under focus. ${ }^{2}$ Any disparities in status positions, as manifested by educational and occupational differentiation, are potentially of a similar significance to more

1 The concept of 'attitude constraint' (Converse, 1964) is built on the assumption of logical and ideological coherence among components); later insights (e.g. Cacioppo et al., 1997) take issue with related bipolar conceptions of the organization of beliefs.

2 See Duclos, et al (2004) with regard to income clustering, and Leitner \& Stehrer (2014) on Gini indices beyond inequalities of wealth. 
immediate structural aspects, such as those entailed by disparities of income. ${ }^{3}$ The inclusion of such distributional parameters in explorative elaborations allows to examine the embedding of satisfaction differentiation with a view to the dual conceptual frames of consolidation and intersection.

Cultural heterogeneity is a further point of interest. A more recent stream of research has found some complex relationships of the prevalence of religiousness with well-being attitudes under various territorial and contextual frames (Okulicz \& Kozaryn 2010). Ideological-political differentiation may have more immediate implications. The mechanisms at work depend on the specificities of distinct political settings, as explained by Jost et al. (2009); they rely on a conception of system justification and its ideological specificities. Distribution characteristics, such as the degree of political polarization, may have a special role in this regard. ${ }^{4}$

\subsection{Regional and Temporal Contexts}

With more than half a dozen years of experience, the European Social Survey (ESS) has yielded rich material for grasping comprehensive patterns, going beyond the reach of country-level one-shot analyses. A growing number of surveys have carried out comparative studies, assessing regional differences and similarities in a variety of topics. This potential for exploitation is far from being reached, although recent attempts to include larger regional entities (Ferrin \& Kriesi, 2014) and pooling data from several waves (Alesina et al, 2004 as forerunners) point toward broader objectives. While the aspects of East and West ${ }^{5}$ are an obvious starting point, the growing European database that the Ess has yields a larger array of options for defining territorial units as a basis of comparison beyond the country level. In differentiating larger regions of the

3 The extent to which subjective indicators follow income positions is a debated issue. Deaton (2008) confirms positive income effects at both individual and aggregate levels of analysis and even points to negative relationships with growth measures. Kahneman \& Deaton (2010) highlight a stronger correlation of evaluative rather than emotional types of satisfaction indicators with income measures. A review by Easterlin (2013) presents a partly different pattern with regard to happiness measures.

4 Ethnic diversity and stratification may also have an important role in related regards as indicated by Haller \& Eder (2015) also in a European context. Data to study such implications was, however, less available in our data-base.

5 As one of the first examples of a synthetic approach, by pooling a longer period of waves of the European Social Survey, Schmitt \& Scheuer (2012) analyse socio-structural and ideological influences on voting for Germany and Europe, with a focus on the East/West dimension. The territorial categories by Helliwell et al. (2014) on a larger global map also apply a similar dual division for the Western and Eastern parts of Europe. 
continent, the institutional frame of belonging to the European Union with the length of membership provides a plausible anchor with formal simplicity and substantive relevance (see the categorization by Leitner \& Stehrer, 2014). Esping-Andersen's typology (1990), based on a variety of institutional setups in the fields of economy and social policy, also offers a fruitful frame with regard to key issues of the present study. This scheme, which is based on the Anglo-Saxon, the Continental and the Scandinavian types of institutional varieties, has been refined by Art \& Gelissen (2002), Fenger (2007) and Holtmann (Holtmann et. al. 2012; Holtmann 2014). The six-element regional typology applied in the following analyses is close to Holtmann's scheme; in addition to the inclusion of the above three varieties, it also distinguishes a Mediterranean segment, and another two as parts of the post-socialist Eastern side, with the latter separation based on their geographical proximity and their intensity of socio-historical ties to the European core. ${ }^{6}$ Russell \& McGinnity (2015) apply a similar regional grouping in a thematic section of a recent Ess-volume on related topics.

In setting the dynamic aspects of our focus, we may rely on the more or less consensual fixing of the breakpoint to the dramatic events of the 2008 financial crash. Most research findings on the effects of the crisis were issued in the United States (e.g. Kenworthy \& Owens 2011; Deaton 2011; Bartels 2013). While impacts on public opinion and political-ideological polarization have been analysed in detail, dispersion-like characteristics have been given less attention. Considering the six waves of the ESS series (2002-2012) available at the start of our analyses, the realization of a before/after component of the study design involves the separation of two periods into three waves each: one from 2002 to 2006 , and the other from 2008 to $2012 .{ }^{7}$ In the empirical part of the paper, we will examine how the crisis affected the level and distribution of general aspects of satisfaction across the different regions in Europe. These elaborations were motivated to a large degree by an interest in the meeting point of two processes of more or less opposite signs: the post-transition convergence of Eastern European countries and the manifestations of the recession period starting with the 2008 financial crisis. It was assumed that joining the European

6 Bohle \& Greskovits (2012) and, in a larger context, Fenger (2007), are some of the few exceptions using a more differentiated approach with regard to transitional paths in Central and Eastern Europe; Riedl \& Haller (2014) apply a categorization similar to our version regarding the CEE countries.

7 Although the timing of ESs fieldwork is usually slightly different in various countries, which was the case with the 2008-2009 wave, the bulk followed the events of the fall 2008 financial crisis. 
Union provided some important leverage with regard to convergence for the countries involved with implications to a levelling of well-being attitudes as well. The crisis, however, may have entailed a counter-effect toward an increase of the degree of polarization of opinions on the one hand, and the strength of correlations (the degree of constraint) between satisfaction with government efficacy and individual satisfaction on the other, with special regard to countries on the Eu periphery. Although our initial interests focused on the regions of Eastern Europe, later analyses paid more attention to other regions (such as the Southern countries) also hit hard by the financial hardships and exhibiting some divergence from the core regions with regard to aspects of satisfaction.

\section{2 \\ Measurement}

Also related to the substantive elements of the theme, our approach builds on certain novel methodological features. Therefore, they need a somewhat longer than usual explanation.

\section{1}

\section{Distribution Measures}

2.1.1 Satisfaction Disparity and Polarization

When analysing consensus or polarization regarding a social issue, standard deviation (or variance) could be a fitting approach; there is, however, a problem related to its heavy dependence on the mean value (a larger mean value implying larger variance). A standard solution to this problem, using a variation coefficient (or relative variance, the simple division of variance with a mean) can have further disadvantages if variables have definite endpoints. For such cases, Delhey and Kohler (2011) propose a metric that takes into account the maximum standard deviation with a given mean value. This statistic is the percent maximum standard deviation (the ratio of the actual standard deviation and the maximum standard deviation) that will be applied as our key measure for the disparities of satisfaction.

Another statistic to measure polarization level is the median share proposed by Wolfson (1994). This is an aggregate ratio of resources (whether of a material character or, as in our case, of perceived well-being) pertaining to the half of the population who are below or above the median value of the given attribute. ${ }^{8}$ Contrary to dispersion measures related to spread in the first place,

8 While Wolfson applied the below median share, for some substantive reasons (for a correspondence in direction with the index of satisfaction disparity, the percentage of the maximum standard deviation) our paper has opted for the above median version of polarization. 
this latter type has more to do with clustering of the population and the contrasts among various segments with regard to certain goods (as highlighted by Wolfson with the term "polarization"). Though much less used in social research than economic analysis, measurement along these lines has substantial social implications. Both measures (the percentage of maximum standard deviation and above median share) will be used in the paper to measure the disparity and polarization of satisfaction in distinct contexts.

\subsubsection{Relative Entropy}

Close to the conceptual frames of consolidation and intersection (Blau, 1994) and partly also similar to Converse's "constraint" (1964) and even more to Martin's "tightness" (2002), the next measure of relative entropy is targeted at the link-up or independence of various aspects of satisfaction. Linearity and the number of dimensions are two conditions of importance. With only two variables and with the expectation of a linear relationship between the variables, the correlation coefficient is a good measure with which to show the strength or lack of connection. Correlation coefficients can also be applied with more than two dimensions, but further options present themselves, such as techniques of principal component or factor analysis, as well as scale reliability methods like Cronbach's Alpha (as used by DiMaggio et al., 1996). Concerning categorical variables of a non-linear relationship and with more than two dimensions, we can apply log-linear or latent-class (LC) methods. The latter also involves the relative entropy ${ }^{9}$ measure highlighted by the following analyses. The higher the value of relative entropy, the stronger the correlation between the manifest variables, and the variable space will be more clustered. A high relative entropy value will point to consolidation, and a low-value intersection

9 The target of the LC model is to divide the sample into clusters where the (manifest) variables included are independent of each other by a multidimensional cross-classification (when local or conditional independence is expected between the manifest variables, see McCutcheon, 1987 and Linzer, 2006). If the manifest variables are jointly independent (as implied by intersection in Blau's terms), a one-class LC model suffices, not needing more constraint for the cross-classification to get local independence; this model is equivalent to the log-linear independence model (Goodman, 1970; Linzer, 2006). If the correlation between the variables (and so the clustering of the population) becomes stronger, just as tightness or the level of constraint grows, we need more classes to reach local independence. To measure the value of intersection level, we have to define the distance between the null model (only one latent class) and the best fitting model. The further the best-fitting model from the null model, the stronger the consolidation aspect of the variables. We measure this distance based on Linzer (2006) with the relative entropy index (also called the Kullback-Leibler divergence), see Equation 1 in the Appendix. 
between our variables..$^{10}$ In this paper, relative entropy will be applied as our key measure for the degree of such constraints.

\subsection{Variables Applied}

We have used the European Social Survey (ESs) research project for the analysis of satisfaction. ${ }^{11}$ The part of questionnaires which related to satisfaction consisted of four variables: life, country economy, government and democracy. All the items were measured on a scale of o-10. Evaluations of personal life and overall circumstances were combined in a joint score of general aspects of satisfaction by averaging the four items above. Besides this simple summary index of the four satisfaction items applied with distribution measures, the additional inclusion of a relative entropy measure allowed for a more differentiated treatment of various satisfaction aspects. All six available waves of Ess research from 2002 to 2012 have been used. ${ }^{12}$ In the latter analysis, we jointly handle data from the pre-crisis period (2002-2007) and the post-crisis period (2008-2013). This period variable will be one of our key indicators in our models. For the pre-crisis period, we have used the first 3 waves of Ess, for the post crisis period we have used Ess 4-6 waves.

For the analyses, we have screened countries to include only those with at least four waves, totalling 25 countries. Although the inclusion of some weighting (e.g. by countries' population size) could be argued for, an equal country weight solution has been elected for this study. As previously explained, data of individual countries have been aggregated to the level of larger regional groups: Scandinavian (Denmark, Finland, Norway and Sweden); Continental (Belgium, Switzerland, Germany, France and the Netherlands); Anglo-Saxon (Great Britain and Ireland); Mediterranean (Cyprus, Spain, Greece, Israel and Portugal); East-Central European (Czech Republic, Poland, Hungary, Slovenia and Slovakia); and East-European (Bulgaria, Estonia, Russia and Ukraine). ${ }^{13}$

10 We have used Linzer \& Lewis's (2011) R package to fit our LC models. Initial items of satisfaction and trust with eleven-point scales were collapsed into items with three categories permitting a non-linear relationship. As also detailed in the following section, the threeclass LC-solution proved best fitting for most of the cases.

11 Initial analyses also dealt with the personal trust variables and the Schwartz test value questions, but this paper focuses only on general aspects of satisfaction.

12 The databases used were: European Social Survey Round 1 to Round 6 Data (2002, 2004, 2006, 2008, 2010, 2012); Data file edition 6.3, 3.3, 3.4, 4.2, 3.1, 2.0; Norwegian Social Science Data Services; Norway - Data Archive and distributor of Ess data.

13 The latter, partly residual type of regional group extending from the Balkans to the Baltics is in many ways quite heterogeneous. Methodological (low-sample case number) and 
Besides the satisfaction measures, four further (aggregate distribution) variables were used in the analysis. These were aggregated from regional survey data, respondents' including the various sociocultural and ideologicalpolitical positions of respondents. Out of these micro-based variables, some macro-statistical contextual variables were also used with regard to the level and pace of economic development of the countries involved, and their immunity to crisis effects (as shown by the change of growth following the 2008 financial crisis). To add more detail regarding the former set, the (relative variance) distribution measure for income positions was built on household net income (thereby applying some imputation as well). ${ }^{14}$ As a second structural variable, the aggregate index of status positions was based on the respondents' education level and their occupation..$^{15}$ The polarization variable, departing from ideological-political positions, relies on the results of preliminary tests which show a heavy dependence on the correlation between a left-right identification and overall satisfaction with the ideological platform of the governing party. ${ }^{16}$ To apply some standardization, a correction has been made to the coding of the left-right scale corresponding to the direction of the correlation in question. ${ }^{17}$ This adjusted variable was used to measure the impact of ideological position (not addressing the direction). Finally, the aggregate variable of diversity of religiousness started out from the individual indicator of religious involvement measured on a $0-10$ scale $(0=$ not at all religious, $10=$ very religious) available in the Ess modules. ${ }^{18}$

As explained earlier, besides the central tendency (mean), further statistics based on the distributional patterns of satisfaction variables have also been used. Technical explanations will follow regarding the measurement

substantive considerations (such as common post-Soviet history) also supported the practice of treating these countries as one grouping.

14 The measure of this variable was changed through the waves. This circumstance on one hand, and a large amount of missing data on the other led to the decision to use regression and discriminant analysis to somewhat balance this bias.

15 It was calculated as the average of time spent in full-time education (maximized to 18 and than halved) and the first digit of Isco code.

16 In the case of left-governed countries the leftists proved more satisfied, while in the case of right-led ones the rightists were.

17 The coding remained where the correlation between pro-government ideological position and satisfaction was positive, and was reversed where a negative correlation was the case by the original scale positions.

18 Table Ar of the Appendix contains correlation coefficients between them and the satisfaction indicators applied, and Table A2 of the Appendix contains basic distributions for the above variables by large regions and periods. 
of satisfaction. At the first stage, measures of mean, standard deviation were computed for all satisfaction variables and for all countries separately. Then the averages were counted for each measure of the four satisfaction variables, resulting in the averages of mean, standard deviation, at the country level. The variation coefficient and the percent maximum standard deviation were calculated at this stage of the work. For the level of larger regional groupings, a further aggregation took place, again resulting in country-group averages.

As far as LC-elaborations are concerned, all the manifest variables have been categorized into three groups (low: 0:3, middle: 4-6, high: 7:10). ${ }^{19}$ Based on preliminary tests, three-class LC solutions were fit to the four satisfaction variables in most cases. Also taking into account the few country-cases where other solutions yielded a better fit, ${ }^{20}$ a uniform class number (of three) was defined, providing an easier interpretation frame. After fitting the 3-class LC models, the relative entropy index was computed, as shown earlier. ${ }^{21}$

Concerning the relationship of the various satisfaction measures and their specific role, the bivariate correlations of Table A1 in the Appendix present some important details. It is noteworthy that the level and the dispersion of satisfaction are in a diagonally different relationship, with practically all attributes taken into consideration. This interesting pattern is directly exhibited by their robust negative correlations (-0.71 and -0.69) for both (pre- and postcrisis) periods. ${ }^{22}$ The correlations between the attributes of dispersion (standard deviation) and relative entropy with highly positive scores but well below 1 indicate that although disparity (or consensus) and tightness of attitudes of satisfaction are closely related, they manifest two distinct aspects. Practically

19 Further categorizations have also been tested and the results have proved stable.

20 The BIC statistic has been applied to measure the goodness of fit (Linzer, 2006). This statistic found the 3 -class solution as best fitting for the large majority of the cases.

21 For a relatively new technique (like LC-based relative entropy for the association of variables in a multi-dimensional space), it seems obvious to examine how it relates to more conventional methods. Such a comparison has been made through principal component analysis (using the original 11-point-scale items at that). Relating the variance in the first principal component to the relative entropy coefficient at the country level, the correlation proved quite high between the two statistics (from 2002 to 2012: 0.93, 0.88, 0.91, 0.74, $0.88,0.96)$. Besides the general resemblance, these findings also point to some divergence of these measures at the 2010 wave, heavily earmarking the crisis period. Complexities in public opinion with special regard to unusual settings also justify the application of nonlinear models.

22 A related negative relationship between level and inequality was pointed out for the aspect of happiness by Ott (2005). 
the same applies for the couple of correlations between the two indicators of dispersion.

\section{$3 \quad$ Results}

\subsection{Economic Development and Crisis Effects}

Although GDP-related indicators are much debated, their universal use and large degree of comparative equivalence warrant their application. ${ }^{23}$ This first set of analyses builds on simple (zero-order) country-level correlations of development and growth indicators with indices of satisfaction for the two periods distinguished with regard to crisis effects. The average per capita GDP and annual growth scores for the two periods (covering three waves each), plus a special indicator of crisis effect defined by the change in growth between the pre- and post-2008 years have been related to four target indicators of level and distribution patterns (disparity, polarization and constraint) of satisfaction.

The results regarding the conventional measure mean are of little surprise in the light of previous findings, showing a clearly positive relationship with levels of development, and a less definite one with growth, even in cases of opposite signs. It is noteworthy, however, that immunity to crisis as measured by the change in growth rates between the two periods covered displays a significant positive correlation for the cases involved (or to put it another way, vulnerable economic conditions appeared hand in hand with lower satisfaction). Results for the distribution measures applied are of special interest with respect to social cohesion. Regarding the level of development as measured by per capita GDP, the findings are fairly unanimous; well-to-do cases tend to be less divided as far as the general mood is concerned (focusing on disparity or polarization as seen by the values for pc-max SD and median share).

Relative entropy, in terms of constraints on satisfaction, has substantive relevance on its own. It indicates a higher level of development accompanied by significantly less internal constraint. To put it another way, it indicates that the distinct attitude facets (as shown by the lesser scores of relative entropy) have more autonomy. These tendencies present themselves more definitely during the period of economic hardship, which may probably be related to some cultural-ideological aspects and processes of political polarization, which will be focused on later in this paper.

23 Dispersion-like indicators such as the Gini-index might also be plausible candidates. However, their usual focus on income and related limitations of comparative validity suggest some reservations. 
TABLE 1 Between-country correlations of satisfaction measures with key economic background indicators, by period (Pearson correlation coefficients; $N=22$ )

\begin{tabular}{|c|c|c|c|c|c|}
\hline & \multicolumn{2}{|c|}{$\begin{array}{l}\text { Level of development } \\
\text { (GDP average level) }\end{array}$} & \multicolumn{2}{|c|}{$\begin{array}{c}\text { Growth } \\
\text { (GDP growth) }\end{array}$} & \multirow{2}{*}{$\begin{array}{l}\text { Crisis effect/ } \\
\text { immunity } \\
\text { (change in } \\
\text { GDP growth) } \\
\text { Period } 2 \text { / } \\
\text { period } 1\end{array}$} \\
\hline & Period $1^{[a]}$ & ${\operatorname{Period~} 2^{[b]}}^{b}$ & Period 1 & Period 2 & \\
\hline $\begin{array}{l}\text { Satisfaction level } \\
\text { (mean) }\end{array}$ & $0.768^{* *}$ & $0.788^{* *}$ & -0.345 & $0.35^{8}$ & $0.573^{* *}$ \\
\hline $\begin{array}{l}\text { Satisfaction disparity } \\
\text { (pc-max standard } \\
\text { deviation) }\end{array}$ & $-0.755^{* *}$ & $-0.781^{* * *}$ & $0.664^{* * *}$ & -0.010 & $-0.501^{* *}$ \\
\hline $\begin{array}{l}\text { Satisfaction polarization } \\
\text { (above median share) }\end{array}$ & $-0.863^{* *}$ & $-0.802^{* * *}$ & $0.467^{*}$ & -0.312 & $-0.547^{* *}$ \\
\hline $\begin{array}{l}\text { Satisfaction constraint } \\
\text { (relative entropy) }\end{array}$ & $-0.45^{*}$ & $-0.600^{* * *}$ & $0.593^{* *}$ & 0.187 & -0.289 \\
\hline
\end{tabular}

[a] Period 1: ESS waves 1-3 (2002-2007). [b] Period 2: ESS waves 4-6 (2008-2013). * sig. level 0.05. ** sig. level o.oo1.

Correlations with growth are less unequivocal than with the aspect of development, but the instances of a significant relationship are not without interest. Fast-paced economic contexts (whether based on low departure or on a typically high accumulation of resources) have tended to have mixed social implications, with a larger degree of disparity and polarization of satisfaction and a kind of tightness of facets during the "normal" periods before 2008. After the 2008 crisis period, relationships ceased to work, having slower or even negative growth in general and related changes in patterns of development.

\subsection{Regional Characteristics}

Assigning the satisfaction variables, the role of dependent variables, the next analysis will go into the differences between European regions and the impact that the crisis had on them. For this, GLM models will be applied, with the region variable as factor, the period variable as covariate ( 0 : before crisis, 1: after crisis). To examine the diverging characteristic of our central variables, we will also add the interaction term of the above-mentioned variables to the model. 
The target variables will remain the three types of distribution measure, besides the indicator of the central tendency of satisfaction.

TABLE 2 Regression model of four satisfaction measures (GLM: ordinal dependent variable, with cumulative logit function)

\begin{tabular}{|c|c|c|c|c|c|c|c|c|}
\hline & \multicolumn{2}{|c|}{$\begin{array}{l}\text { Satisfaction } \\
\text { level (mean) }\end{array}$} & \multicolumn{2}{|c|}{$\begin{array}{c}\text { Satisfaction } \\
\text { disparity (percent- } \\
\text { max. standard dev.) }\end{array}$} & \multicolumn{2}{|c|}{$\begin{array}{l}\text { Satisfaction } \\
\text { polarization } \\
\text { (above median } \\
\text { share) }\end{array}$} & \multicolumn{2}{|c|}{$\begin{array}{c}\text { Satisfaction } \\
\text { constraint } \\
\text { (relative } \\
\text { entropy) }\end{array}$} \\
\hline & $\begin{array}{l}\text { Wald } \\
\text { Chi-Sq }\end{array}$ & Sig. & $\begin{array}{l}\text { Wald } \\
\text { Chi-Sq }\end{array}$ & Sig. & $\begin{array}{l}\text { Wald } \\
\text { Chi-Sq }\end{array}$ & Sig. & $\begin{array}{l}\text { Wald } \\
\text { Chi-Sq }\end{array}$ & Sig. \\
\hline region & 362.37 & 0.000 & 392.8 & 0.000 & 364.09 & 0.000 & 166.2 & 0.000 \\
\hline period & $3 \cdot 5^{1}$ & 0.061 & 2.18 & 0.140 & 0.17 & 0.674 & 24.2 & 0.000 \\
\hline region * period & 43.08 & 0.000 & 10.50 & 0.062 & 41.91 & 0.000 & 8.73 & 0.120 \\
\hline
\end{tabular}

\section{Parameter estimates}

B Sig. $\quad$ B $\quad$ Sig. $\quad$ B $\quad$ Sig. $\quad$ B $\quad$ Sig.

\begin{tabular}{|c|c|c|c|c|c|c|c|c|}
\hline Scandinavian & 7.04 & 0.000 & -6.79 & 0.000 & -6.80 & 0.000 & -3.93 & 0.000 \\
\hline Continental & 4.53 & 0.000 & -6.72 & 0.000 & -5.09 & 0.000 & -2.49 & 0.000 \\
\hline Anglo-Saxon & 1.67 & 0.000 & -3.89 & 0.000 & -2.44 & 0.000 & -2.01 & 0.000 \\
\hline Mediterranean & $1.3^{8}$ & 0.000 & -4.26 & 0.000 & -1.95 & 0.000 & -2.65 & 0.000 \\
\hline East-Central & 1.55 & 0.000 & -2.43 & 0.000 & -1.74 & 0.000 & -0.61 & 0.086 \\
\hline Eastern Eur. & 0 & - & o & - & 0 & - & o & - \\
\hline period $2^{[\mathbf{a}]}$ & -0.55 & 0.197 & -0.361 & 0.402 & -0.30 & 0.484 & -0.35 & 0.444 \\
\hline Scand ${ }^{*}$ period 2 & 0.80 & 0.146 & -0.094 & 0.865 & $-0.5^{8}$ & 0.304 & -0.73 & 0.210 \\
\hline Cont ${ }^{*}$ period 2 & 1.30 & 0.015 & -0.420 & 0.432 & -0.86 & 0.111 & -0.26 & 0.638 \\
\hline Angl-S * period2 & -2.13 & 0.001 & 0.433 & 0.506 & 2.39 & 0.000 & -1.47 & 0.037 \\
\hline Medit ${ }^{*}$ period2 & -0.65 & 0.239 & 1.039 & 0.061 & 1.24 & 0.027 & -0.61 & 0.298 \\
\hline East- $C$ * period 2 & 0.73 & 0.174 & 0.134 & 0.803 & 0.43 & 0.430 & 0.17 & 0.769 \\
\hline Eastern ${ }^{*}$ period 2 & o & - & o & - & o & - & o & - \\
\hline LL Null Model & \multicolumn{2}{|c|}{-488.1} & \multicolumn{2}{|c|}{-485.4} & \multicolumn{2}{|c|}{$-484 \cdot 7$} & \multicolumn{2}{|c|}{$-483 \cdot 3$} \\
\hline LL Model & \multicolumn{2}{|c|}{$-425 \cdot 3$} & \multicolumn{2}{|c|}{-421.4} & \multicolumn{2}{|c|}{-426.7} & \multicolumn{2}{|c|}{$-45^{8.2}$} \\
\hline LL Ratio Chi & \multirow{2}{*}{\multicolumn{2}{|c|}{0.000}} & \multirow{2}{*}{\multicolumn{2}{|c|}{0.000}} & \multirow{2}{*}{\multicolumn{2}{|c|}{0.000}} & \multicolumn{2}{|r|}{0.000} \\
\hline \multicolumn{3}{|l|}{ Square sig. } & & & & & & \\
\hline $\mathrm{N}$ & \multicolumn{2}{|c|}{134} & \multicolumn{2}{|c|}{134} & \multicolumn{2}{|c|}{134} & \multicolumn{2}{|c|}{134} \\
\hline
\end{tabular}

[a] Period 2: ESS waves 4-6 (2008-2013). 
The patterns outlined earlier for the relationship with key economic indicators present a background for the regional variation of the indicators of satisfaction under study. Grade differences between territorial segments appear more or less clearly, becoming even more pronounced through any rearrangement in the wake of crisis phenomena. The effect of period is significant in itself, but its interaction with the regional factor does reveal more detail. In this sense, Anglo-Saxon and especially Mediterranean patterns have more in common with East European segments, and diverge from the less crisis-stricken Scandinavian and Continental regions (a tendency most pronounced with the median share index of satisfaction polarization). These shifts have resulted not only in a fairly clear-cut North/South divide besides the more traditional East/West split, but also in some differentiation among the central regions (in practise, the founder member countries of the European Union) as far as their proximity/distance to the core territories is concerned. Some features of specific measures and regional entities stand out. At the outset of the waves covered, the East European regions which had formerly undergone a heavy period of economic transformation appeared with low scores of perceived well-being (see Delhey \& Newton 2003 in this regard), coupled with high disparity, polarization and tight constraint of satisfaction aspects.

The findings regarding the element of satisfaction constraint in regard to the above patterns are worth highlighting. To summarize its components, the index was based on both private and public aspects of satisfaction. A high score deriving from a close correlation of evaluations regarding these different aspects indicates an anomic state in public thinking embedded in institutional settings. While the related data point towards such durable characteristics with the Eastern regions, the findings for the Mediterranean countries present different characteristics in this respect. Although the Mediterranean countries have different satisfaction measures and polarization actually grew over the period, they displayed less constraint, having somewhat looser links between aspects of opinion than their Eastern counterparts (the lower relative entropy figures mostly derive from the combination of lagging scores of public mood and some endurance of relatively high life satisfaction). And in another difference from the East European pattern, the decrease of overall satisfaction and its growing polarization with the Anglo-Saxon segment did not entail an increase in satisfaction constraints (the opposite was true, resembling the Mediterranean case).

\subsection{A More Complex Syndrome of Satisfaction Stress}

Although the structural and cultural embedding of the variation of satisfaction is evident, their distinct manifestations and specific roles are less obvious. Four 
indices were constructed and deployed by our investigation for the countries in the analysis to measure various aggregate parametersof general aspects of satisfaction. The structural aspects were approached by measures of inequalities of income positions on the one hand, and a combined index of educational and occupational disparities on the other. As seen in Table A 1 in the Appendix, the correlations are much stronger for the latter than the former with both the level and dispersion of satisfaction for both periods, which clearly indicates that income inequalities are of more immediate relevance for perceptions of well-being. ${ }^{24}$

The aspects of cultural-ideological cleavages were represented by an index of polarization on the left-right scale (corrected for standard deviation as with the case of satisfaction) mirroring distances between voters of incumbent and opposition parties and, on the other hand, an index of the diversity of religiousness (based on the differentiation of religious participation). The first measure (see Table A 1 in the Appendix) displays a significant negative relationship with the level (as a consequence of the construction of the variable), and a positive one, with the disparity of satisfaction manifesting themselves more strongly for the pre-crisis period, probably having to do with the generally more hectic fluctuations in the government and opposition roles following the 2008 financial crisis. Although plain correlations indicate no significant relationship between the diversity of religiousness and attributes of satisfaction, this pattern will present itself more clearly with the next multivariate analyses.

Going beyond the level of bivariate correlations, a more complex scheme of relationships is outlined by a factorial model including the set of aggregate satisfaction indicators and the structural and cultural-ideological attributes introduced above. With this, a syndrome becomes clear, with elements of stress of the general mood under various settings. A strong link between these elements also entails a certain complementarity with regard to producing discontent with matters as a whole.

24 As seen in the basic data of Table A2 in the Appendix, a certain convergence can be observed for larger regions with regard to educational-occupational status differentials, which becomes smaller in relation to gaps in income positions. This kind of disparity may have become more palpable with the gradual opening of the labor market following the enlargement of the European Union. 
TABLE 3 A country-level stress syndrome of satisfaction, a factorial model by period (PCA analysis, 1 principal component extracted)

\begin{tabular}{|c|c|c|}
\hline & $\operatorname{Period}_{1}[\mathrm{a}]$ & $\operatorname{Period} 2^{[b]}$ \\
\hline satisfaction level (mean) & -0.897 & -0.919 \\
\hline $\begin{array}{l}\text { satisfaction disparity (percent-max. } \\
\text { standard deviation) }\end{array}$ & $0.85^{8}$ & 0.844 \\
\hline $\begin{array}{l}\text { satisfaction polarization (above } \\
\text { median share) }\end{array}$ & 0.916 & 0.921 \\
\hline satisfaction constraint (relative entropy) & $0.5^{18}$ & 0.438 \\
\hline $\begin{array}{l}\text { status positions' disparity (educational- } \\
\text { occupational relative variance) }\end{array}$ & 0.510 & 0.501 \\
\hline $\begin{array}{l}\text { income positions' inequality (imputed } \\
\text { income relative variance) }\end{array}$ & 0.918 & 0.925 \\
\hline $\begin{array}{l}\text { ideological-political polarization (left-right } \\
\text { scale, percent-max. std. dev.) }\end{array}$ & 0.537 & 0.289 \\
\hline $\begin{array}{l}\text { religiousness diversity (degree of religious } \\
\text { involvement std. dev.) }\end{array}$ & -0.048 & -0.279 \\
\hline$\%$ of variance explained & $5^{0.5}$ & 48.3 \\
\hline $\mathrm{N}$ & 62 & 72 \\
\hline
\end{tabular}

[a] Period 1: ESS waves 1-3 (2002-2007). [b] Period 2: ESS waves 4-6 (2008-2013).

The factorial model displays a basically consistent pattern of components for both periods involved. We can observe a syndrome with opposite signs for the level and disparities of satisfaction, and with somewhat lesser loadings, the latter pattern is followed by the measure of constraint of satisfaction facets, including relative entropy. The low level of satisfaction, and a high degree of its dispersion, plus a tight constraint of attitudes can be regarded as the core of the syndrome. Its character manifests itself more clearly by rather strong ties with further contextual attributes. The inequality of income positions becomes, therefore, salient. The degree of left-right polarization is an ideological-political element of the syndrome with a marked role (though, as indicated above with earlier analyses, some of its decrease in the crisis period may possibly be related to rearrangements of political landscapes and the emergence of newer dividing lines). Lastly, an attenuating relationship of the stress 
syndrome with a diversity of religious involvement seems a new phenomenon within the European context.

We examined the regional and temporal differentiation of this stress syndrome with regression models. We applied the same logic as earlier: the dependent variable was the stress syndrome, and the independent variables were the region, period and the interaction of the two indicators. To go deeper we added three GDP related indicators to a second model (see Table 4).

Although this analysis does not go into the complexities of causal mechanisms, ${ }^{25}$ it shows the impact of the degree of consolidation with regard to elements and background traits of perceived well-being. The stress syndrome, as outlined by the above factorial model, increases with the degree of correlation among various elements of the syndrome. The juncture of components (such as disparities of satisfaction and tightness of its facets) is of no necessity either from a mathematical, or a substantive point of view; its occurrence may actually be a part of the problem. The substantial gap that can be observed in Table 4 for the large regions of Europe is due on the one hand to the distribution of the components of the syndrome (as also seen in Table A2 in the Appendix) and the various degrees of their correlations. It deserves attention again that in spite of certain convergences of some of these components, the satisfaction gap has not decreased as a whole; it actually increased in some ways during the crisis period between core regions of Europe and and the periphery. ${ }^{26}$ While the general pattern of satisfaction stress, the order of re-

25 Even if level of satisfaction may be naturally conceived as an outcome variable for the model outlined, feedback effects may readily come into play (low perceived well-being, or large disparities thereof may trigger corrective mechanisms depending on institutional settings).

26 The findings presented above have been based on aggregate-level analyses, which is a legitimate approach regarding the distributional measures in focus. A supplementary analysis was, however, also carried out regarding the role of some individual-level variables in differences among larger regional units. These elaborations definitely confirmed the dominant influence of income position for various aspects of satisfaction that actually increased during the periods covered in the majority of cases. Out of the culturalideological variables, supporting or opposing attitudes toward the government (as indicated by left-right positions in a given country) is a further significant component of the model, which also strengthened with the crisis period, especially in the Eastern regions, and East Central Europe in particular. The positive influence of religious involvement on life satisfaction (see Okulicz \& Kozaryn, 2010) was also confirmed by these individual-level analyses, although this influence has lost some of its significance over the periods covered. 
TABLE 4 Hierarchal regression models of country-level stress syndrome of satisfaction (GLM: ordinal dependent variable, with cumulative logit function)

\begin{tabular}{lcccc}
\hline & \multicolumn{2}{c}{ Model 1 } & \multicolumn{2}{c}{ Model 2 } \\
& Wald & Sig. & Wald & Sig. \\
& Chi-Sq & & Chi-Sq & \\
& & & & \\
\hline & & & & \\
Model variables & 585.5 & 0.000 & 201.1 & 0.000 \\
region & 0.06 & 0.779 & 1.8 & 0.178 \\
period & 55.26 & 0.000 & 102.0 & 0.000 \\
region * period & - & - & 309.40 & 0.000 \\
GDP level (2002-07) & - & - & $129 \cdot 7$ & 0.000 \\
GDP growth (2002-07) & - & - & 95.9 & 0.000 \\
Crisis effect / immunity & & & & \\
(change in growth period 2 / & & & & \\
period 1) & & & &
\end{tabular}

Parameter estimates

B Sig. $\quad$ B $\quad$ Sig.

Region effects

Scandinavian

Continental

Anglo-Saxon

Mediterranean

East-Central

$-8.59$

0.000

$-5.24$

0.000

$-7 \cdot 79$

0.000

$-4.71$

0.000

$-4.62$

0.000

0.34

o.619

$-1.76$

0.000

$-1.62$

0.004

Eastern Eur.

$-2.5^{1}$

0.000

$-2.44$

0.000

0

o

Period effect

$\operatorname{period} 2^{[a]}$

0.295

$-0.41$

0.414

Region * period interaction effects

$\begin{array}{lclcl}\text { Scand * period2 } & -0.88 & 0.109 & -0.74 & 0.159 \\ \text { Cont * period2 } & -1.88 & \mathbf{0} & -\mathbf{1 . 3 8} & \mathbf{0 . 0 0 8} \\ \text { Angl-S * period2 } & 1.17 & 0.062 & 2.69 & \mathbf{0} \\ \text { Medit * period2 } & 0.13 & 0.813 & 1.31 & \mathbf{0 . 0 1 5} \\ \text { East-C * period2 } & -1.31 & \mathbf{0 . 0 1 5} & -0.46 & 0.368 \\ \text { Eastern * period2 } & 0 & & 0 & \end{array}$


TABLE 4 Hierarchal regression models of country-level stress syndrome of satisfaction (cont.)

\begin{tabular}{|c|c|c|c|}
\hline & $\begin{array}{c}\text { Model } 1 \\
\text { Parameter estimates }\end{array}$ & \multicolumn{2}{|c|}{ Model 2} \\
\hline & Sig. & B & Sig. \\
\hline \multicolumn{4}{|l|}{ Development effects } \\
\hline GDP level (2002-07) & & -0.10 & 0.000 \\
\hline GDP growth (2002-07) & & -0.14 & 0.000 \\
\hline $\begin{array}{l}\text { Crisis effect / immunity } \\
\text { (change in growth period } 2 / \\
\text { period } 1 \text { ) }\end{array}$ & & -12.31 & 0.000 \\
\hline LL Null Model & -508 & & -508 \\
\hline LL Model & -435 & & -402.2 \\
\hline LL Ratio Chi Square sig. & $<.001$ & & $<.001$ \\
\hline $\mathrm{N}$ & 120 & & 120 \\
\hline
\end{tabular}

[a] Period 2: ESS waves 4-6 (2008-2013).

gions remained more or less the same. What is more, no period effect could be observed for the entire set of regions as a whole, although some subtler details point to certain rearrangements. So the interaction terms displaying the joint effect of period and region variables indicate a partial distancing from the regional bottom represented by the Eastern European region. Model 1 indicates such a shift for the Continental region in the first place (coming close to the Scandinavian region with the lowest degree of satisfaction stress). However, some element of convergence from the periphery to the core was also presented by the respective data for East Central Europe. By also controlling for the contextual variables of economic development with Model 2, the general pattern keeps its shape on the whole, but a reverse trend toward a higher level of stress exhibits itself significantly for the Anglo-Saxon and Mediterranean regions. The latter trend may be conceived as an element of divergence within the inner domain of the more established EU-regions.

\section{$4 \quad$ Summary}

The key lessons of our study emphatically suggest the methodological consideration that conventionally applied measures like central tendency should 
be supplemented by structural parameters of distribution. In demonstrating these attempts, the study presents data on various types of measures of general aspects of satisfaction and their positive relationships with the level of economic development and somewhat more mixed evidence with economic growth. At the same time it presents new findings of a solid correlation of general aspects of satisfaction with immunity to crisis as measured by the differential of growth rates before and after the 2008 crisis. The inclusion of dispersion-like measures provides insights into satisfaction which are not evident in previous research. Data on the degree of differentiation point to a stronger polarization of public mood under deteriorating contexts and, to a certain degree, conditions of vulnerability to economic downturn. The recently introduced measure of relative entropy for the tightness of attitude facets brings further shade, with a more rigid juncture of mood components at a lower level of development. Results on larger regions of Europe generally agree with these patterns, taking economic maturity and exposure to the crisis into account. The six-element typology of larger regions of Europe presents a pronounced picture of these tendencies for both the East/West and the North/ South divides. The consequences of financial crisis broadened the gaps even among core members of the European Union, showing a divergence of the Mediterranean region from the Scandinavian and Continental patterns, in particular as far as inner polarization of opinions is concerned. East Central and especially Eastern segments also exhibit a higher than average level of attitude constraint (as measured by relative entropy), whereas the Nordic region stands out with a lesser degree of constraint in this respect (see Delhey \& Newton, 2005, and their phrase "Nordic exceptionalism" for related contexts).

In an explorative search for aspects of embedding of satisfaction variation, a limited set of structural and cultural-ideological traits has been selected to test their contextual relevance. Out of the attributes included, the distribution of income positions proved to have a key role; high inequality in this respect is accompanied by large disparities of content and discontent in distinct countries. These differences are clearly observable at the level of larger regions across Europe. Various characteristics of general aspects of satisfaction tend to constitute a consolidated pattern as a stress syndrome of satisfaction. They mirror the various degrees of discontent and internal strains across larger regions of Europe. These gaps did not diminish throughout the periods covered by the present study, which may also be ascribed to the crisis phenomena after 2008, as indicated above. Digging further into the character of these and other components at various levels of analysis may shed new light on leverages of social cohesion and, in turn, on conditions of anomie on a larger scale. 


\section{References}

Alesina, A., Di Tella, R. \& MacCulloch, R., (2004) 'Inequality and happiness: are Europeans and Americans different?', Journal of Public Economics, 88(9-10), pp.20092042. http://dx.doi.org/10.1016/j.jpubeco.2003.07.006

Arts, W. \& Gelissen, J., (2002) 'Three worlds of welfare capitalism or more? A stateof-the-art report' Journal of European Social Policy, 12(2), pp.137-158. http://dx.doi .org/10.1177/0952872002012002114

Bartels, L. M., (2013) 'Political Effects of the Great Recession' The ANNALS of the American Academy of Political and Social Science, 650(1), pp.47-76. http://dx.doi .org/10.1177/0002716213496054

Blau, P. M. (1994) Stuctural Contexts of Opportunities. Chicago: The University of Chicago Press.

Bohle, D. \& Greskovits, B. (2012) Capitalist diversity on Europe's periphery. Cornell University Press.

Cacioppo, J. T., Gardner, W. L. \& Berntson, G. G., (1997) 'Beyond Bipolar Conceptualizations and Measures: The Case of Attitudes and Evaluative Space', Personality and Social Psychology Review, 1(1), pp.3-25. http://dx.doi.org/10.1207/ s15327957pspro101_2

Converse, Phil E. (1964) The Nature of Belief Systems in Mass Publics. In David Apter, ed. Ideology and Discontent. New York: Free Press.

Deaton, A., (2008) 'Income, Health, and Well-Being around the World: Evidence from the Gallup World Poll', Journal of Economic Perspectives, 22(2), pp.53-72. http:// dx.doi.org/10.1257/jep.22.2.53

Deaton, A., (2011) 'The financial crisis and the well-being of Americans: 2011 OE P Hicks Lecture*', Oxford Economic Papers, 64(1), pp.1-26. http://dx.doi.org/10.1093/oep/ gpro51

Delhey, J. \& Newton, K., (2003) 'Who trusts?: The origins of social trust in seven societies', European Societies, 5(2), pp.93-137. http://dx.doi.org/10.1080/1461669032000072256

Delhey, J. \& Newton, K., (2005) 'Predicting Cross-National Levels of Social Trust: Global Pattern or Nordic Exceptionalism?', European Sociological Review, 21(4), pp.311-327. http://dx.doi.org/10.1093/esr/jcio22

Delhey, J., \& Kohler U. (2011) 'Is Happiness Inequality Immune to Income Inequality? New Evidence Through Instrument-Effect-Corrected Standard Deviations'. Social Science Research 40(3), pp.742-56

DiMaggio, P, Evans J. \& Bryson B., (1996) 'Have Americans' social attitudes become more polarized?' American Journal of Sociology, 102(3) pp. 690-755. http://dx.doi .org/10.1086/230995

Duclos, J.-Y., Esteban, J., \& Ray, D. (2004) 'Polarization: Concepts, Measurement, Estimation' Econometrica, 72(6), pp.1737-1772. doi:10.1111/j.1468-0262.2004.00552.X 
Easterlin, R A. (2013) 'Happiness and Economic Growth: The Evidence'. IZA Discussion Paper No. 7187. Available at ssRn: http://ssrn.com/abstract $=2210847$

Esping-Andersen, G. (1990) The Three Worlds of Welfare Capitalism. Princeton: Princeton University Press

Ferrin, M., \& Kriesi, H. (2014). 'Europeans' Understandings and Evaluations of Democracy: Topline Results from Round 6 of the European Social Survey.' ess Topline Results Series, (4). Available online at: http://www.europeansocialsurvey. org/ permalink/80oea36f-3a8d-11e4-95d4-005056b8065f.pdf.

Goodman, L. A. (1970) 'The Multivariate Analysis of Qualitative Data: Interactions among Multiple Classifications', Journal of the American Statistical Association, 65(329), p.226. doi:10.2307/2283589

Haller, M., \& Eder, A. (2015). Ethnic Stratification and Economic Inequality Around the World. The End of Exploitation and Exclusion? Farnham/Surrey: Ashgate.

Helliwell, J. F. \& Wang, S. (2014) 'Measuring Subjective Well-being: Theory and Practice in Korea'. In: Wang, S. ed. (2014) Measuring and Explaining Subjective Well-being in Korea. Seoul: Korean Development Institute.

Holtmann, D., Buchheister, C., Görl, T., Mutz, M., \& Schuster, A. (2012) Die Sozialstruktur der Bundesrepublik Deutschland im internationalen Vergleich. Universitätsverlag Potsdam.

Holtmann, D. (2014) Wohlstand und Wohlfahrt der Nationen im Wandel. Aachen: Shaker Verlag

Jost, J. T., C. M. Federico, \& J. L. Napier (2009) 'Political Ideology: Its Structure, Functions, and Elective Affinities'. Annual Review of Psychology (6o), pp.307-37.

Kahneman, D., \& Deaton, A. (2010) 'High income improves evaluation of life but not emotional well-being', Proceedings of the National Academy of Sciences, 107(38), pp.16489-16493. doi:10.1073/pnas.1011492107

Kenworthy L. \& Owens L. A. (2011) 'How Do Economic Recessions Influence Public Opinion' In Grusky, D. B., Western B. \& Wimer C., (ed,) The Great Recession. New York, NY: Russell Sage Foundation

Leitner, S. \& Stehrer, R. (2014) Drivers of Inequality and Poverty in the CEE and other EU Member States (No. 398). The Vienna Institute for International Economic Studies, wiiw.

Linzer, D. A. (2006) Ideological Constraint and the Quality of Governance in New and Established Democracies, http://tercer.bol.ucla.edu/workshop/linzero6.pdf

Linzer D. A. \& Lewis J. B. (2011) 'poLCA: An R package for polytomous variable latent class analysis', Journal of Statistical Software, 42(10), pp.1-29

Martin, J. L. (2002) 'Power, Authority, and the Constraint of Belief Systems', American Journal of Sociology, 108(2), 531-531. doi:10.1086/374817

McCutcheon A. L. (1987): Latent class analysis. Quantitative Applications in the Social Sciences Series No. 64. Thousand Oaks, California: Sage Publications. 
Mikucka, M., \& Sarracino, F., \& Dubrow J. K. (2017): 'When Does Economic Growth Improve Life Satisfaction? Multilevel Analysis of the Roles of Social Trust and Income Inequality in 46 Countries, 1981-2012' World Development (93) pp.447-459.

Okulicz-Kozaryn, A. (2010): 'Religiosity and life satisfaction across nations' Mental Health, Religion \& Culture (13), pp.155-169.

Ott, J. (2005) 'Level and Inequality of Happiness in Nations. Does Greater Happiness of a Greater Number Imply Greater Inequality in Happiness?' Journal of Happiness Studies (4), pp.397-420.

Riedl, F. \& Haller M. (2014) 'From socialist equality to capitalist stratification: How people see it', Corvinus Journal of Sociology and Social Policy, pp.3-33. doi:10.14267/ cjssp.2014.01.01

Russell, H. \& McGinnity F. (2015) 'Feeling balanced. Perceived work-life balance and working conditions in Europe' in:Measuring and Reporting on Europeans'Wellbeing: Findings from the European Social, Ess Eric.

Sarracino, F., \& Mikucka, M. (2015): 'Social capital in Europe from 1990 to 2012: trends, path-dependency and convergence.' Social Indicators Research (131) pp.407-432.

Schmitt, H., \& Scheuer, A. (2012). 'Parteien und Wahlen'. In S. Keil \& J. van Deth (eds.), Metamorphosen. Baden-Baden: Nomos, pp.209-236.

Simmel, G. (1955) Conflict and the web of group affliations. Simon and Schuster.

Wolfson, M. C. (1994) 'When inequalities diverge'. The American Economic Review (84.2), pp.353-358.

\section{Statistical Programs Used}

SPSS

$\mathrm{R} 2.15 .2$

R Core Team (2012). R: A language and environment for statistical computing. R Foundation for Statistical Computing, Vienna, Austria. ISBN 3-900051-07-0, http:// www.r-project.org

\section{Appendix}

Equation 1, Relative Entropy:

$$
\frac{D_{K L}(P \| Q)}{\sum_{i} P(i)[\log P(i)-\log Q(i)]}
$$

$\mathbf{P}(\mathbf{i})$ is the probability density function estimated by the multi-class latent class model. $\mathbf{Q}(\mathbf{i})$ is the "null" independence model, and $\mathbf{i}$ indexes the cells of the observed cross-classification table of survey variables. 
TABLE A1 Country-level correlations of two satisfaction measures with further traits of attitude and structural and cultural differentiation, by period

\begin{tabular}{|c|c|c|c|}
\hline & & $\begin{array}{l}\text { Satisfaction } \\
\text { level (mean) }\end{array}$ & $\begin{array}{c}\text { Satisfaction } \\
\text { disparity (percent- } \\
\text { max. standard dev.) }\end{array}$ \\
\hline satisfaction polarization & Period ${ }_{1}^{[a]}$ & $-0.873^{* *}$ & $0.737^{* *}$ \\
\hline (above median share) & Period $2^{[b]}$ & $-0.917^{* *}$ & $0.765^{* *}$ \\
\hline satisfaction constraint & Period 1 & $-0.337^{* *}$ & $0.596^{* *}$ \\
\hline (relative entropy) & Period 2 & -0.214 & $0.66 \mathrm{o}^{* *}$ \\
\hline status positions' disparity & Period 1 & $-0.400^{* *}$ & 0.167 \\
\hline $\begin{array}{l}\text { (educational-occupational } \\
\text { relative variance) }\end{array}$ & Period 2 & $-0.464^{* *}$ & 0.086 \\
\hline income positions' inequality & Period 1 & $-0.783^{* *}$ & $0.700^{* *}$ \\
\hline $\begin{array}{l}\text { (imputed income relative } \\
\text { variance) }\end{array}$ & Period 2 & $-0.854^{* *}$ & $0.688^{* *}$ \\
\hline ideological-political & Period 1 & $-0.404^{* *}$ & $0.397^{* *}$ \\
\hline $\begin{array}{l}\text { polarization } \\
\text { (percent-max. standard dev.) }\end{array}$ & Period 2 & -0.122 & $0.291^{*}$ \\
\hline $\begin{array}{l}\text { religiousness diversity } \\
\text { (degree of religiousness; }\end{array}$ & Period 1 & -0.145 & 0.005 \\
\hline standard deviation) & Period 2 & 0.181 & -0.081 \\
\hline
\end{tabular}

[a] Period 1: EsS waves 1-3 (2002-2007). [b] Period 2: ESS waves 4-6 (2008-2013). * sig. level 0.05 . ** sig. level 0.001 . 
TABLE A2 Average scores of country-level structural and cultural measures, by region and period

\begin{tabular}{|c|c|c|c|}
\hline $\begin{array}{c}\text { Status positions' } \\
\text { disparity } \\
\text { (educational } \\
\text { occupational relative } \\
\text { variance) }\end{array}$ & $\begin{array}{l}\text { Income positions' } \\
\text { inequality } \\
\text { (imputed income } \\
\text { relative variance) }\end{array}$ & $\begin{array}{c}\text { Ideological-political } \\
\text { polarization } \\
\text { (percent-max. } \\
\text { standard deviation) }\end{array}$ & $\begin{array}{c}\text { Religiousness } \\
\text { diversity } \\
\text { (degree of } \\
\text { religiousness; } \\
\text { standard deviation) }\end{array}$ \\
\hline Period $2^{[b]}$ & Period 2 & $d_{1}$ & $\operatorname{riod} 1$ Period 2 \\
\hline
\end{tabular}

\begin{tabular}{|c|c|c|c|c|c|c|c|c|}
\hline \multicolumn{9}{|l|}{ European regions } \\
\hline Scandinavian & 0.28 & 0.27 & 0.43 & 0.42 & 0.42 & 0.43 & 2.65 & 2.75 \\
\hline Continental & 0.27 & 0.26 & 0.47 & 0.47 & 0.40 & 0.40 & 2.94 & 3.02 \\
\hline Anglo-Saxon & 0.26 & 0.26 & 0.46 & 0.55 & 0.35 & 0.36 & 2.66 & 2.76 \\
\hline Mediterranian & 0.39 & 0.34 & 0.65 & 0.67 & 0.46 & 0.48 & 2.53 & 2.72 \\
\hline East Central & 0.30 & 0.28 & 0.63 & 0.63 & 0.47 & 0.48 & 2.82 & 2.89 \\
\hline \multicolumn{9}{|l|}{ Europe } \\
\hline Eastern & 0.32 & 0.30 & 0.79 & 0.76 & 0.45 & 0.43 & 2.75 & 2.71 \\
\hline \multicolumn{9}{|l|}{ Europe } \\
\hline Total & 0.30 & 0.29 & 0.56 & 0.59 & 0.43 & 0.44 & 2.75 & 2.82 \\
\hline $\mathrm{F}$ & $17 \cdot 9$ & $7 \cdot 7$ & 33.6 & 30.6 & $7 \cdot 9$ & 10.6 & $5 \cdot 4$ & 2.9 \\
\hline sig. & 0.000 & 0.000 & 0.000 & 0.000 & 0.000 & 0.000 & 0.000 & 0.017 \\
\hline eta squared & 0.616 & 0.367 & $0.75^{\circ}$ & 0.699 & 0.415 & 0.445 & 0.326 & 0.184 \\
\hline
\end{tabular}

[a] Period 1: ESS waves 1-3 (2002-2007). [b] Period 2: ESS waves 4-6 (2008-2013). 